Acta Crystallographica Section E

Structure Reports

Online

ISSN 1600-5368

\section{Marcus V. N. de Souza, Solange M. S. V. Wardell ${ }^{\mathrm{a}}$ and R. Alan Howie ${ }^{b *}$}

${ }^{\text {a}}$ Fundaçâo Oswaldo Cruz, Far-Manguinhos, Rua Sizenando Nabuco 100, Manguinhos, 21041250 Rio de Janeiro, RJ, Brazil, and ${ }^{\mathbf{b}}$ Department of Chemistry, University of Aberdeen, Meston Walk, Aberdeen AB24 3UE, Scotland

Correspondence e-mail: r.a.howie@abdn.ac.uk

\section{Key indicators}

Single-crystal X-ray study

$T=120 \mathrm{~K}$

Mean $\sigma(\mathrm{C}-\mathrm{C})=0.004 \AA$

$R$ factor $=0.054$

$w R$ factor $=0.133$

Data-to-parameter ratio $=18.0$

For details of how these key indicators were automatically derived from the article, see http://journals.iucr.org/e.

\title{
2-Chloropyridine-3-carboxylic acid
}

The molecules of the title compound, $\mathrm{C}_{6} \mathrm{H}_{4} \mathrm{ClNO}_{2}$, are almost completely planar. Hydrogen bonds of the form $\mathrm{O}-\mathrm{H} \cdots \mathrm{N}$ interconnect the molecules to form infinite chains, which are also planar and which are packed face-to-face to form well defined layers of molecules.

\section{Comment}

The title compound, (I), the fortuitous product of an unsuccessful reaction, has proved to be identical to commercially available 2-chloronicotinic acid whose structure has not as yet, as far as we know, been reported. This report makes good this deficiency.<smiles>O=C(O)c1cccnc1Cl</smiles>

The molecule is shown in Fig. 1. The bond lengths and angles are unremarkable and are not discussed here. The molecule is, however, remarkably planar. The r.m.s. deviation of the fitted atoms when the plane is defined by all ten non- $\mathrm{H}$ atoms is $0.0279 \AA$, as against $0.0049 \AA$ when only the six atoms of the pyridine ring define the plane. The largest displacements from the least-squares plane of the pyridine ring are those of $\mathrm{O} 2$ and $\mathrm{Cl} 1$, at 0.096 (5) and 0.034 (4) $\AA$, respectively. The torsion angles given in Table 1 , in which the greatest deviation from ideal values is $2.5(4)^{\circ}$, provide another indication of the planarity of the molecule. $\mathrm{O}-\mathrm{H} \cdots \mathrm{N}$ hydrogen bonds (Table 2) connect the molecules to form infinite chains, which, because the dihedral angle between the least-squares planes of the pyridine rings of adjacent molecules is only $1.35(16)^{\circ}$, are more accurately described as ribbons. The ribbons of hydrogen-bonded molecules are packed face-to-

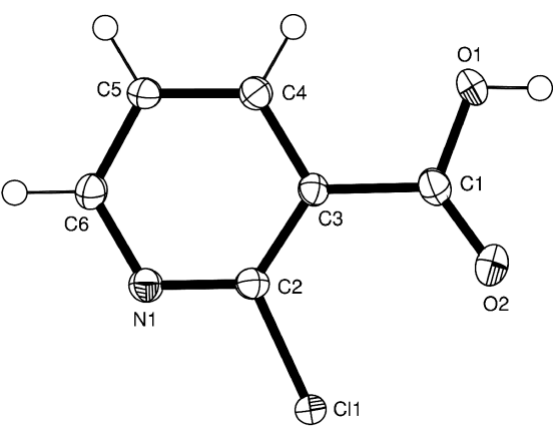

Figure 1

A view of (I). Displacement ellipsoids are drawn at the $50 \%$ probability level and $\mathrm{H}$ atoms are shown as small circles of arbitrary radii.
Received 22 March 2005

Accepted 1 April 2005

Online 16 April 2005
(C) 2005 International Union of Crystallography Printed in Great Britain - all rights reserved 
face, with only van der Waals interactions between them, to form well defined layers such as that centred on $y=\frac{3}{4}$, shown in Fig. 2. The symmetry relationship between neighbouring molecules within each ribbon involves cell translation parallel to $c$, along with the operation of the $a$-glide plane perpendicular to $b$, whereas the relationship between neighbouring ribbons in the layer is entirely due to the operation of the $a$ glide. It is noticeable that in the layer shown in Fig. 2, which straddles the $a$-glide plane at $y=\frac{3}{4}$, the flat surfaces of the hydrogen-bonded ribbons are parallel to (201). The immediate neighbours of the layer shown in Fig. 2, e.g. that centred on $y=\frac{1}{4}$, are related to it by the operation of a crystallographic $n$-glide perpendicular to $a$. As a consequence, the flat surfaces of the ribbons of molecules in these neighbouring layers are now parallel to (201). Thus, ideally and in the absence of disorder in the stacking of the layers in the $b$ direction, the ribbons alternate in orientation from one layer to the next. The layer surfaces are populated by $\mathrm{Cl}$ atoms and by the $\mathrm{H}$ atoms attached to $\mathrm{C} 5$ and $\mathrm{C} 6$ of the pyridine rings. As a consequence, only van der Waals forces operate at the layer interface and there is no well defined means of controlling the stacking of the layers, which presumably explains the twinning evident in the sample crystal. The evidence for twinning lies in the fact that twin refinement was required, in the value finally obtained for the Flack (1983) $x$ parameter and in the presence of a large number of weak but apparently statistically significant $\left[F^{2}>10 \sigma\left(F^{2}\right)\right] 0 k l$ reflections, which should in fact be systematically absent. It is suggested that the twinning in the sample crystal is responsible for the disappointingly high residual peaks in the final electron density map.

Recourse to the Cambridge Structural Database (CSD; Version 5.26; Allen, 2002) by means of the EPSRC's Chemical Database Service at Daresbury (Fletcher et al., 1996) has provided data for the structures of compounds analogous to (I). Discussed here are those of 5-iodopyridine-3-carboxylic acid at $223 \mathrm{~K}$, (II) (CSD refcode XIHFEZ; Lu \& Babb, 2002), nicotinic acid, (III) (NICOAC02; Kutoglu \& Scheringer, 1983), and 6-fluoronicotinic acid, (IV) (YEHQEH; Wangler et al., 2001). The structures of (II) and (III) contain $\mathrm{O}-\mathrm{H} \cdots \mathrm{N}$ hydrogen-bonded ribbons of essentially planar molecules, very similar to those observed in (I). In contrast, in (IV), O$\mathrm{H}$... O hydrogen bonds create centrosymmetric dimers with, in the formalism of Bernstein et al. (1995), an $R_{2}^{2}(8)$ motif. In (II), the ribbons are propagated in the same manner, with a combination of cell translation and the operation of a crystallographic glide plane, as they are in (I), but in (III) neighbouring molecules are related by the operation of a crystallographic twofold screw axis. In (II), just as in (I), the ribbons are arranged face-to-face and are related to one another by the operation of a crystallographic $c$-glide plane, forming layers parallel to (010) and centred on $y=\frac{1}{4}$ and $\frac{3}{4}$, with I atoms on the layer surfaces. The flat ribbon surfaces and therefore the planar molecules of (II) are once again parallel to (102). Now, however, neighbouring layers are related to one another by the operation of crystallographic centres of symmetry, which, from one layer to the next, changes the polarity of the hydrogen bonding within the ribbons but not

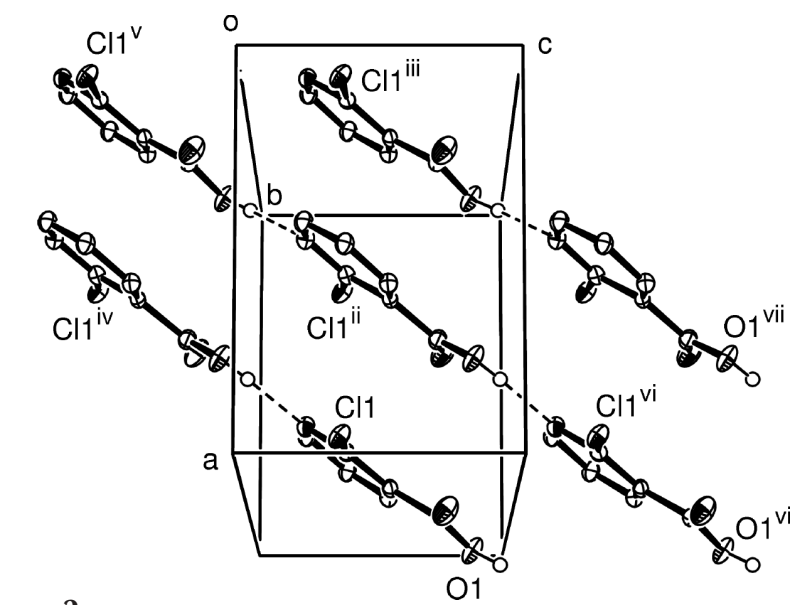

Figure 2

A layer of molecules in (I). Displacement ellipsoids are drawn at the 50\% probability level and $\mathrm{H}$ atoms involved in hydrogen bonds (dashed lines) are shown as small circles of arbitrary radii. [Symmetry codes: (ii) $x-\frac{1}{2}$, $\frac{3}{2}-y, z$; (iii) $x-1, y, z$; (iv) $x-\frac{1}{2}, \frac{3}{2}-y, z-1$; (v) $x-1, y, z-1$; (vi) $x, y$, $1+z ;$ (vii) $x-\frac{1}{2}, \frac{3}{2}-y, 1+z$.]

their orientation within the cell. In (III), the ribbons of hydrogen-bonded molecules form layers parallel to (001) and centred on $z=\frac{1}{4}$ and $\frac{3}{4}$, within which the ribbons are packed edge-to-edge rather than face-to-face as in (I). The layers in (III) are stacked in the $c$ direction and are related to one another by the operation of crystallographic centres of symmetry, and it is here, in the stacking of the layers, that the face-to-face arrangement of the ribbons occurs.

\section{Experimental}

Compound (I) was isolated from an attempted reaction involving 2-chloronicotinoyl chloride and 4-pyridinylhydrazine and was identical to a commercial sample. A reaction mixture of 2-chloronicotinoyl chloride $(2 \mathrm{mmol})$ and isoniazid hydrochloride (4pyridinylCONHNH $2 \cdot \mathrm{HCl})(2 \mathrm{mmol})$ in THF $(20 \mathrm{ml})$ and excess $\mathrm{Et}_{3} \mathrm{~N}$ were refluxed for $6 \mathrm{~h}$, concentated and the residue column chromatographed, with hexane/ethyl acetate as eluent. The title compound was shown to be the major product and to be identical to the commercially available acid (Aldrich), m.p. > 397 K. The sample used in the X-ray crystallographic determination was recrystallized from EtOH.

\section{Crystal data \\ $\mathrm{C}_{6} \mathrm{H}_{4} \mathrm{ClNO}_{2}$ \\ $M_{r}=157.55$ \\ Orthorhombic, Pna2 \\ $a=8.2741(2) \AA$ \\ $b=13.1807$ (5) $\AA$ \\ $c=5.7182(3) \AA$ \\ $V=623.62(4) \AA^{3}$ \\ $Z=4$ \\ $D_{x}=1.678 \mathrm{Mg} \mathrm{m}^{-3}$}

Mo $K \alpha$ radiation

Cell parameters from 994 reflections

$\theta=1.1-36.3^{\circ}$

$\mu=0.54 \mathrm{~mm}^{-1}$

$T=120(2) \mathrm{K}$

Slab, colourless

$0.30 \times 0.30 \times 0.08 \mathrm{~mm}$

\section{Data collection}

Nonius KappaCCD diffractometer $\varphi$ and $\omega$ scans

Absorption correction: multi-scan (SADABS; Sheldrick, 2003)

$T_{\min }=0.691, T_{\max }=0.960$

6798 measured reflections

1689 independent reflections

$$
\begin{aligned}
& 1539 \text { reflections with } I>2 \sigma(I) \\
& R_{\text {int }}=0.043 \\
& \theta_{\max }=31.0^{\circ} \\
& h=-10 \rightarrow 11 \\
& k=-16 \rightarrow 18 \\
& l=-8 \rightarrow 7
\end{aligned}
$$




\section{Refinement}

Refinement on $F^{2}$ $R\left[F^{2}>2 \sigma\left(F^{2}\right)\right]=0.055$

$w R\left(F^{2}\right)=0.133$

$S=1.19$

1689 reflections

94 parameters

$\mathrm{H}$-atom parameters constrained

$w=1 /\left[\sigma^{2}\left(F_{\mathrm{o}}^{2}\right)+(0.0634 P)^{2}\right.$

$+0.5322 P]$

where $P=\left(F_{\mathrm{o}}{ }^{2}+2 F_{\mathrm{c}}{ }^{2}\right) / 3$

\section{Table 1}

Selected torsion angles $\left({ }^{\circ}\right)$.

\begin{tabular}{lrlr}
\hline $\mathrm{C} 2-\mathrm{C} 3-\mathrm{C} 1-\mathrm{O} 1$ & $177.9(3)$ & $\mathrm{C} 1-\mathrm{C} 3-\mathrm{C} 2-\mathrm{Cl} 1$ & $-2.1(4)$ \\
$\mathrm{C} 2-\mathrm{C} 3-\mathrm{C} 1-\mathrm{O} 2$ & $-2.1(5)$ & $\mathrm{C} 4-\mathrm{C} 3-\mathrm{C} 2-\mathrm{Cl} 1$ & $178.3(2)$ \\
$\mathrm{C} 4-\mathrm{C} 3-\mathrm{C} 1-\mathrm{O} 1$ & $-2.5(4)$ & $\mathrm{C} 6-\mathrm{N} 1-\mathrm{C} 2-\mathrm{Cl} 1$ & $-179.4(2)$ \\
$\mathrm{C} 4-\mathrm{C} 3-\mathrm{C} 1-\mathrm{O} 2$ & $177.5(3)$ & & \\
\hline
\end{tabular}

\section{Table 2}

Hydrogen-bond geometry $\left(\AA,^{\circ}\right)$.

\begin{tabular}{lllll}
\hline$D-\mathrm{H} \cdots A$ & $D-\mathrm{H}$ & $\mathrm{H} \cdots A$ & $D \cdots A$ & $D-\mathrm{H} \cdots A$ \\
\hline $\mathrm{O} 1-\mathrm{H} 1 \cdots \mathrm{N} 1^{\mathrm{i}}$ & 0.84 & 1.85 & $2.687(4)$ & 178 \\
\hline
\end{tabular}

Symmetry code: (i) $x+\frac{1}{2},-y+\frac{3}{2}, z+1$.

In the final stages of refinement, aryl $\mathrm{H}$ atoms were placed in calculated positions, with $\mathrm{C}-\mathrm{H}=0.95 \AA$, and refined with a riding model, with $U_{\text {iso }}(\mathrm{H})=1.2 U_{\text {eq }}(\mathrm{C})$. The hydroxy $\mathrm{H}$ atom was placed as for an idealized $\mathrm{OH}$ group, with $\mathrm{O}-\mathrm{H}=0.84 \mathrm{~A}$ and with a torsion angle compatible with calculated electron density, and then refined with a riding model, with $U_{\text {iso }}(\mathrm{H})=1.5 U_{\text {eq }}(\mathrm{O})$, along with further refinement of the torsion angle. The Flack (1983) parameter, while indicative of partial inversion twinning, is attributed primarily to irregularities in the stacking of the layers of molecules in the $b$-axis direction, as mentioned in the Comment.

Data collection: COLLECT (Hooft, 1998); cell refinement: DENZO (Otwinowski \& Minor, 1997) and COLLECT; data reduction: DENZO and COLLECT; program(s) used to solve structure: SHELXS97 (Sheldrick, 1997); program(s) used to refine structure: SHELXL97 (Sheldrick, 1997); molecular graphics: ORTEP-3 for Windows (Farrugia, 1997); software used to prepare material for publication: SHELXL97 and PLATON (Spek, 2003).

The use of both the EPSRC's X-ray crystallographic service at Southampton, England, and the Chemical Database Service at Daresbury, England, is gratefully acknowledged.

\section{References}

Allen, F. H. (2002). Acta Cryst. B58, 380-388.

Bernstein, J., Davis, R. E., Shimoni, L. \& Chang, N.-L. (1995). Angew. Chem. Int. Ed. Engl. 34, 1555-1573.

Farrugia, L. J. (1997). J. Appl. Cryst. 30, 565.

Flack, H. D. (1983). Acta Cryst. A39, 876-881.

Fletcher, D. A., McMeeking, R. F. \& Parkin, D. (1996). J. Chem. Inf. Comput. Sci. 36, 746-749.

Hooft, R. W. W. (1998). COLLECT. Nonius BV, Delft, The Netherlands.

Kutoglu, A. \& Scheringer, C. (1983). Acta Cryst. C39, 232-234.

Lu, J. Y. \& Babb, A. M. (2002). Inorg. Chem. 41, 1339-1341.

Otwinowski, Z. \& Minor, W. (1997). Methods in Enzymology, Vol. 276, Macromolecular Crystallography, Part A, edited by C. W. Carter Jr \& R. M. Sweet, pp. 307-326. New York: Academic Press.

Sheldrick, G. M. (1997). SHELXS97 and SHELXL97. University of Göttingen, Germany.

Sheldrick, G. M. (2003). SADABS. Version 2.10. Bruker AXS Inc., Madison, Wisconsin, USA.

Spek, A. L. (2003). J. Appl. Cryst. 36, 7-13.

Wangler, B., Rosch, F. \& Schollmeyer, D. (2001). Private Communication from the Institut Für Organische Chemie, Universität Mainz, Germany. 


\section{supporting information}

Acta Cryst. (2005). E61, o1347-o1349 [https://doi.org/10.1107/S160053680501024X]

\section{2-Chloropyridine-3-carboxylic acid}

Marcus V. N. de Souza, Solange M. S. V. Wardell and R. Alan Howie

2-Chloropyridine-3-carboxylic acid

Crystal data

$\mathrm{C}_{6} \mathrm{H}_{4} \mathrm{ClNO}_{2}$

$M_{r}=157.55$

Orthorhombic, Pna $_{1}$

$a=8.2741(2) \AA$

$b=13.1807(5) \AA$

$c=5.7182(3) \AA$

$V=623.62(4) \AA^{3}$

$Z=4$

$F(000)=320$

$D_{\mathrm{x}}=1.678 \mathrm{Mg} \mathrm{m}^{-3}$

Mo $K \alpha$ radiation, $\lambda=0.71073 \AA$

Cell parameters from 994 reflections

$\theta=1.1-36.3^{\circ}$

$\mu=0.54 \mathrm{~mm}^{-1}$

$T=120 \mathrm{~K}$

Slab, colourless

$0.30 \times 0.30 \times 0.08 \mathrm{~mm}$

\section{Data collection}

Nonius KappaCCD diffractometer

Radiation source: Bruker-Nonius FR591 rotating anode

$10 \mathrm{~cm}$ confocal mirrors monochromator

Detector resolution: 9.091 pixels $\mathrm{mm}^{-1}$

$\varphi$ and $\omega$ scans

Absorption correction: multi-scan

(SADABS; Sheldrick, 2003)

$T_{\min }=0.691, T_{\max }=0.960$

6798 measured reflections

1689 independent reflections

1539 reflections with $I>2 \sigma(I)$

$R_{\text {int }}=0.043$

$\theta_{\max }=31.0^{\circ}, \theta_{\min }=2.9^{\circ}$

$h=-10 \rightarrow 11$

$k=-16 \rightarrow 18$

$l=-8 \rightarrow 7$

\section{Refinement}

Refinement on $F^{2}$

Least-squares matrix: full

$R\left[F^{2}>2 \sigma\left(F^{2}\right)\right]=0.055$

$w R\left(F^{2}\right)=0.133$

$S=1.19$

1689 reflections

94 parameters

1 restraint

Primary atom site location: structure-invariant direct methods

Secondary atom site location: difference Fourier map

Hydrogen site location: inferred from neighbouring sites

$\mathrm{H}$-atom parameters constrained

$w=1 /\left[\sigma^{2}\left(F_{\mathrm{o}}^{2}\right)+(0.0634 P)^{2}+0.5322 P\right]$ where $P=\left(F_{\mathrm{o}}^{2}+2 F_{\mathrm{c}}^{2}\right) / 3$

$(\Delta / \sigma)_{\max }<0.001$

$\Delta \rho_{\max }=1.03$ e $\AA^{-3}$

$\Delta \rho_{\min }=-0.76 \mathrm{e} \AA^{-3}$

Extinction correction: SHELXL97, $\mathrm{Fc}^{*}=\mathrm{kFc}\left[1+0.001 \times \mathrm{Fc}^{2} \lambda^{3} / \sin (2 \theta)\right]^{-1 / 4}$

Extinction coefficient: 0.160 (15)

Absolute structure: Flack (1983), 706 Friedel pairs

Absolute structure parameter: 0.39 (12) 


\section{Special details}

Experimental. Unit cell determined with DIRAX (Duisenberg, 1992; Duisenberg et al. 2000) but refined with the DENZO/COLLECT HKL package.

Refs as: Duisenberg, A. J. M. (1992). J. Appl. Cryst. 25, 92-96. Duisenberg, A. J. M., Hooft, R. W. W., Schreurs, A. M. M. \& Kroon, J. (2000). J. Appl. Cryst. 33, 893-898.

Geometry. All e.s.d.'s (except the e.s.d. in the dihedral angle between two 1.s. planes) are estimated using the full covariance matrix. The cell e.s.d.'s are taken into account individually in the estimation of e.s.d.'s in distances, angles and torsion angles; correlations between e.s.d.'s in cell parameters are only used when they are defined by crystal symmetry. An approximate (isotropic) treatment of cell e.s.d.'s is used for estimating e.s.d.'s involving 1.s. planes.

Least-squares planes $(x, y, z$ in crystal coordinates) and deviations from them (* indicates atom used to define plane) $6.6280(59) x-0.1555(162) y-3.4222(55) z=3.6653(188)$

* $0.0031(0.0020) \mathrm{N} 1 \_\$ 1 * 0.0037(0.0019) \mathrm{C} 2 \_\$ 1 *-0.0075(0.0019) \mathrm{C} 3 \_\$ 1 * 0.0048(0.0020) \mathrm{C} 4 \_\$ 1 * 0.0018$ $(0.0022)$ C5_\$1*-0.0060 (0.0022) C6_\$1

Rms deviation of fitted atoms $=0.0049$

$6.6280(60) x+0.1555(163) y-3.4222(55) z=4.0067(150)$

Angle to previous plane (with approximate e.s.d.) $=1.35(0.16)$

$* 0.0031(0.0020) \mathrm{N} 1 * 0.0037(0.0019) \mathrm{C} 2 *-0.0075(0.0019) \mathrm{C} 3 * 0.0048(0.0020) \mathrm{C} 4 * 0.0018(0.0022) \mathrm{C} 5 *-0.0060$

(0.0022) C6 - $0.0402(0.0048)$ C1 0.0008 (0.0052) O1 - 0.0964 (0.0054) O2 0.0335 (0.0040) C11

Rms deviation of fitted atoms $=0.0049$

$6.6791(28) x+0.1062(75) y-3.3747(26) z=4.0234(67)$

Angle to previous plane (with approximate e.s.d.) $=0.63(13)$

$*{ }_{-} 0.0079(0.0023) \mathrm{N} 1 * 0.0071(0.0024) \mathrm{C} 2 * 0.0062(0.0026) \mathrm{C} 3 * 0.0127(0.0025) \mathrm{C} 4 *-0.0054(0.0024) \mathrm{C} 5 *-0.0224$ (0.0026) C6 * $0.0101(0.0025) \mathrm{C} 1 * 0.0381(0.0020) \mathrm{O} 1 *-0.0604(0.0021) \mathrm{O} 2 * 0.0421(0.0015) \mathrm{C} 11$

Rms deviation of fitted atoms $=0.0279$

Refinement. Refinement of $F^{2}$ against ALL reflections. The weighted $R$-factor $w R$ and goodness of fit $S$ are based on $F^{2}$, conventional $R$-factors $R$ are based on $F$, with $F$ set to zero for negative $F^{2}$. The threshold expression of $F^{2}>\sigma\left(F^{2}\right)$ is used only for calculating $R$-factors(gt) etc. and is not relevant to the choice of reflections for refinement. $R$-factors based on $F^{2}$ are statistically about twice as large as those based on $F$, and $R$-factors based on ALL data will be even larger. Aryl $\mathrm{H}$ atoms placed in calculated positions with $\mathrm{C}-\mathrm{H}=0.95 \mathrm{~A}$ and refined with a riding model with $U_{\text {iso }}(\mathrm{H})=$ 1.2 $\mathrm{Ueq}(\mathrm{C})$. Hydroxyl $\mathrm{H}$ placed as for an idealized $\mathrm{OH}$ group with $\mathrm{O}-\mathrm{H}=0.84 \mathrm{~A}$ and with torsion angle compatible with calculated electron density and then refined with a riding model with $U_{\text {iso }}(\mathrm{H})=1.5 U_{\text {eq }}(\mathrm{O})$ along with further refinement of the torsion angle.

Fractional atomic coordinates and isotropic or equivalent isotropic displacement parameters $\left(\AA^{2}\right)$

\begin{tabular}{lllll}
\hline & $x$ & $y$ & $z$ & $U_{\text {iso }} * / U_{\text {eq }}$ \\
\hline C11 & $0.77160(8)$ & $0.61579(4)$ & $0.34183(16)$ & $0.0220(2)$ \\
O1 & $1.0326(3)$ & $0.80953(16)$ & $0.8657(5)$ & $0.0273(5)$ \\
H1 & 1.0800 & 0.7779 & 0.9733 & $0.041^{*}$ \\
O2 & $0.9634(3)$ & $0.65368(18)$ & $0.7529(5)$ & $0.0325(6)$ \\
N1 & $0.6902(3)$ & $0.79347(19)$ & $0.2012(5)$ & $0.0195(5)$ \\
C1 & $0.9567(3)$ & $0.7440(2)$ & $0.7277(5)$ & $0.0199(6)$ \\
C2 & $0.7754(3)$ & $0.7467(2)$ & $0.3639(5)$ & $0.0167(5)$ \\
C3 & $0.8625(3)$ & $0.7967(2)$ & $0.5380(5)$ & $0.0154(5)$ \\
C4 & $0.8583(4)$ & $0.9026(2)$ & $0.5311(5)$ & $0.0181(6)$ \\
H4 & 0.9172 & 0.9405 & 0.6438 & $0.022 *$ \\
C5 & $0.7696(3)$ & $0.9529(2)$ & $0.3624(6)$ & $0.0190(6)$ \\
H5 & 0.7663 & 1.0249 & 0.3584 & $0.023 *$ \\
C6 & $0.6854(4)$ & $0.8958(2)$ & $0.1991(5)$ & $0.0196(6)$ \\
H6 & 0.6230 & 0.9294 & 0.0833 & $0.024 *$ \\
\end{tabular}


Atomic displacement parameters $\left(\AA^{2}\right)$

\begin{tabular}{lllllll}
\hline & $U^{11}$ & $U^{22}$ & $U^{33}$ & $U^{12}$ & $U^{13}$ & $U^{23}$ \\
\hline C11 & $0.0289(4)$ & $0.0141(3)$ & $0.0230(4)$ & $-0.0013(2)$ & $-0.0100(4)$ & $0.0002(3)$ \\
O1 & $0.0359(12)$ & $0.0238(10)$ & $0.0221(11)$ & $-0.0003(8)$ & $-0.0147(11)$ & $-0.0001(9)$ \\
O2 & $0.0420(14)$ & $0.0233(11)$ & $0.0322(13)$ & $-0.0002(10)$ & $-0.0139(12)$ & $0.0075(10)$ \\
N1 & $0.0231(13)$ & $0.0190(12)$ & $0.0164(12)$ & $-0.0021(9)$ & $-0.0009(11)$ & $0.0009(9)$ \\
C1 & $0.0189(12)$ & $0.0239(14)$ & $0.0169(13)$ & $-0.0027(11)$ & $-0.0016(12)$ & $0.0023(11)$ \\
C2 & $0.0187(11)$ & $0.0164(11)$ & $0.0152(13)$ & $-0.0017(9)$ & $0.0014(11)$ & $-0.0006(13)$ \\
C3 & $0.0168(12)$ & $0.0173(12)$ & $0.0120(11)$ & $0.0019(10)$ & $0.0011(11)$ & $-0.0005(10)$ \\
C4 & $0.0202(13)$ & $0.0182(12)$ & $0.0160(13)$ & $0.0002(10)$ & $0.0002(11)$ & $-0.0003(11)$ \\
C5 & $0.0235(13)$ & $0.0163(11)$ & $0.0172(15)$ & $-0.0001(9)$ & $-0.0016(12)$ & $-0.0016(14)$ \\
C6 & $0.0228(14)$ & $0.0186(13)$ & $0.0174(14)$ & $0.0008(10)$ & $-0.0011(12)$ & $0.0028(10)$ \\
\hline
\end{tabular}

Geometric parameters $\left(\AA,{ }^{\circ}\right)$

\begin{tabular}{llll}
\hline $\mathrm{C} 11-\mathrm{C} 2$ & $1.730(3)$ & $\mathrm{C} 2-\mathrm{C} 3$ & $1.394(4)$ \\
$\mathrm{O} 1-\mathrm{C} 1$ & $1.328(4)$ & $\mathrm{C} 3-\mathrm{C} 4$ & $1.396(4)$ \\
$\mathrm{O} 1-\mathrm{H} 1$ & 0.8400 & $\mathrm{C} 4-\mathrm{C} 5$ & $1.382(4)$ \\
$\mathrm{O} 2-\mathrm{C} 1$ & $1.201(4)$ & $\mathrm{C} 4-\mathrm{H} 4$ & 0.9500 \\
$\mathrm{~N} 1-\mathrm{C} 2$ & $1.320(4)$ & $\mathrm{C} 5-\mathrm{C} 6$ & 0.9500 \\
$\mathrm{~N} 1-\mathrm{C} 6$ & $1.349(4)$ & $\mathrm{C} 5-\mathrm{H} 5$ & 0.9500 \\
$\mathrm{C} 1-\mathrm{C} 3$ & $1.505(4)$ & $\mathrm{C} 6-\mathrm{H} 6$ & $119.6(3)$ \\
$\mathrm{C} 1-\mathrm{O} 1-\mathrm{H} 1$ & 109.5 & $\mathrm{C} 4-\mathrm{C} 3-\mathrm{C} 1$ & $120.8(3)$ \\
$\mathrm{C} 2-\mathrm{N} 1-\mathrm{C} 6$ & $119.2(3)$ & $\mathrm{C} 5-\mathrm{C} 4-\mathrm{C} 3$ & 119.6 \\
$\mathrm{O} 2-\mathrm{C} 1-\mathrm{O} 1$ & $123.5(3)$ & $\mathrm{C} 5-\mathrm{C} 4-\mathrm{H} 4$ & 119.6 \\
$\mathrm{O} 2-\mathrm{C} 1-\mathrm{C} 3$ & $124.6(3)$ & $\mathrm{C} 3-\mathrm{C} 4-\mathrm{H} 4$ & $118.4(3)$ \\
$\mathrm{O} 1-\mathrm{C} 1-\mathrm{C} 3$ & $111.9(2)$ & $\mathrm{C} 4-\mathrm{C} 5-\mathrm{C} 6$ & 120.8 \\
$\mathrm{~N} 1-\mathrm{C} 2-\mathrm{C} 3$ & $123.9(3)$ & $\mathrm{C} 4-\mathrm{C} 5-\mathrm{H} 5$ & 120.8 \\
$\mathrm{~N} 1-\mathrm{C} 2-\mathrm{C} 11$ & $113.8(2)$ & $\mathrm{C} 6-\mathrm{C} 5-\mathrm{H} 5$ & $11.5(3)$ \\
$\mathrm{C} 3-\mathrm{C} 2-\mathrm{C} 11$ & $122.2(2)$ & $\mathrm{N} 1-\mathrm{C} 6-\mathrm{C} 5$ & 119.3 \\
$\mathrm{C} 2-\mathrm{C} 3-\mathrm{C} 4$ & $116.1(3)$ & $\mathrm{N} 1-\mathrm{C} 6-\mathrm{H} 6$ & $-2.1(4)$ \\
$\mathrm{C} 2-\mathrm{C} 3-\mathrm{C} 1$ & $124.3(2)$ & $\mathrm{C} 5-\mathrm{C} 6-\mathrm{H} 6$ & $178.3(2)$ \\
& & & $-179.4(2)$ \\
$\mathrm{C} 2-\mathrm{C} 3-\mathrm{C} 1-\mathrm{O} 1$ & $177.9(3)$ & $\mathrm{C} 1-\mathrm{C} 3-\mathrm{C} 2-\mathrm{C} 11$ & \\
$\mathrm{C} 2-\mathrm{C} 3-\mathrm{C} 1-\mathrm{O} 2$ & $-2.1(5)$ & $\mathrm{C} 4-\mathrm{C} 3-\mathrm{C} 2-\mathrm{C} 11$ & \\
$\mathrm{C} 4-\mathrm{C} 3-\mathrm{C} 1-\mathrm{O} 1$ & $-2.5(4)$ & $\mathrm{C} 6-\mathrm{N} 1-\mathrm{C} 2-\mathrm{C} 11$ & \\
$\mathrm{C} 4-\mathrm{C} 3-\mathrm{C} 1-\mathrm{O} 2$ & $177.5(3)$ & &
\end{tabular}

Hydrogen-bond geometry $\left(A,{ }^{\circ}\right)$

\begin{tabular}{lllll}
\hline$D-\mathrm{H} \cdots A$ & $D-\mathrm{H}$ & $\mathrm{H} \cdots A$ & $D \cdots A$ & $D-\mathrm{H} \cdots A$ \\
\hline $\mathrm{O} 1-\mathrm{H} 1 \cdots \mathrm{N} 1^{\mathrm{i}}$ & 0.84 & 1.85 & $2.687(4)$ & 178 \\
\hline
\end{tabular}

Symmetry code: (i) $x+1 / 2,-y+3 / 2, z+1$. 